\title{
KIR3DS1/L1 and HLA-Bw4-80I are associated with HIV disease progression among HIV typical progressors and long-term nonprogressors
}

\author{
Yongjun Jiang ${ }^{1,2 \dagger}$, Ou Chen ${ }^{1,2,3}$, Chen Cui ${ }^{1,2}$, Bin Zhao ${ }^{1,2}$, Xiaoxu Han ${ }^{1,2}$, Zining Zhang ${ }^{1,2}$, Jing Liu ${ }^{1,2}$, Junjie Xu $u^{1,2}$,
} Qinghai $\mathrm{Hu}^{1,2}$, Christina Liao ${ }^{1,2}$ and Hong Shang ${ }^{1,2^{*+}}$

\begin{abstract}
Background: Natural killer (NK) cells have emerged as pivotal players in innate immunity, especially in the defense against viral infections and tumors. Killer immunoglobulin-like receptors (KIRs) - an important recognition receptor expressed on the surface of NK cells - regulate the inhibition and/or activation of NK cells after interacting with human leukocyte antigen (HLA) class I ligands. Various KIR genes might impact the prognosis of many different diseases. The implications of KIR-HLA interaction in HIV disease progression remains poorly understood.
\end{abstract}

Methods: Here, we studied KIR genotypes, mRNA levels, HLA genotypes, CD4 ${ }^{+} \mathrm{T}$ cell counts and viral loads in our cohort of Human Immunodeficiency Virus (HIV)-infected individuals, a group that includes HIV long-term nonprogressors (LTNPs) and typical progressors (TPS).

Results: We found that the frequency of KIR3DS1/L1 heterozygotes with HLA-Bw4-80l gene was much higher in LTNPs than in TPS $(P=0.001)$ and that the KIR3DL1 homozygotes without HLA-Bw4-80l gene had higher viral loads and lower $C D 4^{+} T$ cell counts $(P=0.014$ and $P=0.021$, respectively). Our study also confirmed that homozygosity for the HLA-Bw6 allele was associated with rapid disease progression. In addition to the aforementioned results on the DNA level, we observed that higher level expression of KIR3DS1 mRNA was in LTNP group, and that higher level expression of KIR3DL1 mRNA was in TP group.

Conclusions: Our data suggest that different KIR-HLA genotypes and different levels of transcripts associate with HIV disease progression.

Keywords: Natural killer (NK) cells, Killer immunoglobulin-like receptors (KIRs), Human immunodeficiency virus (HIV), Long-term nonprogressor (LTNP), Typical progressor (TP)

\section{Background}

Natural killer (NK) cells play a vital role in innate immune response because of their ability to kill virusinfected cells, to produce cytokines, and to communicate with the adaptive immune system. NK cell activation is controlled by complex interactions between activating or inhibitory receptors and their associated ligands. Of these receptors, the killer immunoglobulin-like receptors

\footnotetext{
* Correspondence: hongshang100@hotmail.com

${ }^{\dagger}$ Equal contributors

'Key Laboratory of AIDS Immunology of Ministry of Health, Department of Laboratory Medicine, The First Affiliated Hospital, China Medical University, Shenyang 110001 , P. R. China

${ }^{2}$ Collaborative Innovation Center for Diagnosis and Treatment of Infectious Diseases, Hangzhou, China

Full list of author information is available at the end of the article
}

(KIRs), which interact with human leukocyte antigen (HLA) class I ligands on the surface of target cells, are the main receptors that recognize the presence or absence of antigens on cell surface [1,2].

The KIR region, located on chromosome 19q13.4, is highly polymorphic in humans, and the polygenic KIR gene complex codes for varying numbers of inhibitory and activating receptors [3]. To date, 14 KIR genes and two pseudogenes have been discovered. KIRs contain two or three external immunoglobulin-like domains (KIR2D, KIR3D) with either long (L) or short (S) cytoplasmic tails, corresponding to their function as inhibitory or activating receptors, respectively [1,4-6]. HLA class I genes, located on chromosome 6p21.3, are KIR

\section{Biomed Central}


ligands. The degree of NK cell inhibition and/or activation is regulated by interactions between KIR and HLA class I gene products [7]. Both KIR and HLA genes exhibit remarkable diversity and rapid evolution, suggesting that they are governed by pathogen-mediated selection and that they influence disease outcomes in individuals [8].

Indeed, several disease association studies have indicated that interactions between KIR and HLA class I ligands play a role in controlling infectious diseases, autoimmune/ inflammatory disorders, cancers and reproduction diseases $[1,3]$. The KIR3DS1 gene and the HLA-Bw4-80I gene, have reported links to the slowing down of Human Immunodeficiency Virus (HIV) disease progression. However, some researchers have drawn different, even opposing, conclusions [9-14]. The relationship between the KIR3DL1 allele and HIV disease progression is also full of controversy. KIR3DL1, which segregates as an allele of the KIR3DS1 gene, is supposed to have an inhibitory function on NK cell activity. A study by Carr, W.H. et al., revealed that KIR3DL1 contributes to an inhibitory response when bound to HLA-Bw4 ligands [15]. Several studies also showed that the presence of inhibitory allele KIR3DL1 in combination with the HLA-B*57 s alleles that contain the Bw4-80I epitope had a highly protective effect against progression to AIDS [16,17].

Besides the above research, other KIRs had also been reported to be associated with HIV disease progression. Specifically, Gaudieri, S, et al., found that KIR2DS2/L2 was associated with more rapid decline in $\mathrm{CD} 4^{+} \mathrm{T}$ cells and a faster progression towards AIDS [13]. In addition, Soria, A. et al., found that the functional compound genotype HLA-C1(+)/KIR2DL3(+), was associated with reduced risk of immunological no responder status in treated HIV-infected individuals [18].

Long-term nonprogressors (LTNPs), who experience markedly slower disease progression and represent 2\% to $5 \%$ of HIV-infected individuals [19], serve as an ideal model for studying the biological mechanisms of the slow progression to AIDS [20]. However, the KIR genes of LTNPs have rarely been studied and require further investigation.

Previous studies on the association between HIV disease progression and the interaction of KIRs and their ligands focused mainly on DNA data. However, studying these genes at the transcriptional level could provide more relevant information in protein function. Nevertheless, data related to relative quantitative mRNA expressions of KIR in HIV-infected individuals were seldom reported. One study reported that high levels of simian immunodeficiency virus (SIV) replication were associated with significant increases in KIR3DL mRNA levels among SIV-infected rhesus macaques [21]. The nature of the association between KIR mRNA and HIV disease progression is still unclear.
In this report, we explored the associations between HIV disease progression and the following factors: the KIR genes, the HLA genes, the combination of these genes, and mRNA levels in HIV-infected individuals.

\section{Methods \\ Study population}

A total of $132 \mathrm{HIV}$-seropositive individuals, including 40 selective LTNPs, were recruited for this study, all of whom were Chinese and ethnically Han, the predominant ethnic group in China. All HIV-seropositive individuals were grouped according to their $\mathrm{CD}^{+} \mathrm{T}$ cell counts. If their $\mathrm{CD} 4^{+} \mathrm{T}$ cell counts were above 500 cells/ $\mu \mathrm{l}$, we put them in the "high $\mathrm{CD} 4^{+} \mathrm{T}$ cell count" group. If their $\mathrm{CD}^{+} \mathrm{T}$ cell counts were below 500 cells/ $\mu$ l, we put them in the "low $\mathrm{CD}^{+} \mathrm{T}$ cell count" group. According to these criteria, 49 individuals belonged to the "high $\mathrm{CD} 4^{+} \mathrm{T}$ cell count" group and 83 individuals belonged to the "low $\mathrm{CD} 4{ }^{+} \mathrm{T}$ cell count" group. The individuals were then grouped according to HIV viral loads. Of these individuals, 84 individuals who had viral loads more than $10^{4}$ copies $/ \mathrm{ml}$ were placed in the "high viral load" group, and 48 individuals who had viral loads less than $10^{4}$ copies $/ \mathrm{ml}$ were placed in the "low viral load" group. Finally, individuals were grouped according to HIV disease progression; the LTNP group was composed of 40 individuals who had no history of antiretroviral therapy and maintained $\mathrm{CD}^{+}{ }^{+} \mathrm{T}$ cell counts above 500 cells/ $\mu$ l for more than 10 years of confirmed HIV infection. The TP group was composed of 83 individuals who also had no history of antiretroviral therapy and whose $\mathrm{CD}^{+} \mathrm{T}$ cell counts had dropped lower than 500 cells/ $\mu$ l. The KIR genotypes, HLA genotypes, $\mathrm{CD}^{+} \mathrm{T}$ cell counts and viral loads for all study participants were determined. The Research and Ethics Committee of The First Affiliated Hospital of China Medical University approved the study, and each studied individual gave written informed consent for participation in the study.

\section{KIR and HLA genotyping}

Genomic DNA was extracted from whole blood samples of HIV-seropositive individuals using QIAamp DNA Mini Kits (Qiagen, Germany) according to the manufacturer's instructions. KIR and HLA genotypings were done by performing PCR-SSP (polymerase chain reaction sequence-specified primer) using the KIR Genotyping SSP Kit (Tianjin Super Biotechnology Development Corporation, China) and Micro SSP ${ }^{\mathrm{TM}}$ Generic HLA Class I DNA Typing Tray (One Lambda, Inc, USA). KIR genotyping was performed using PCR amplification with primers specific for each locus (PCR-SSP). Internal control primers for a 588-bp conserved fragment of the human growth hormone (HGH) were also included in each PCR. Two sets of primers were used for each locus. The 
presence or absence of KIR genes was determined by comparing with the standard provided by the manufacturer.

\section{Analysis of nucleotides and amino acids of HLA-B}

HLA-B genotyping was done by performing PCR-SSP. Genomic DNA from HIV-seropositive individuals was used as a template. Amplification primers Bx1 (5'GGGAGGAGCGAGGGGACC(G/C)CAG-3') and BINT3 (5'-GGAGGCCATCCCCGGCGACCTAT-3') allowed amplification of an HLA-B-specific product of about 1000 base pairs. The purified HLA-B amplification product was used as a template for direct cycle-sequencing reactions, and HLA-Bw4-80I was characterized by the presence of isoleucine at position 80 of the second exon from the C- terminus.

\section{Determination of $\mathrm{CD}^{+} \mathrm{T}$ cell counts}

$\mathrm{CD} 4^{+} \mathrm{T}$ cell counts were measured using a FACSCalibur flow cytometer (BD Bioscience, San Jose, CA, USA). A single-platform lyse-no-wash procedure was performed using TruCOUNT tubes and TriTEST anti-CD4-FITC/ CD8-PE/CD3-PerCP reagents (BD, USA). TruCOUNT Control beads (low, median and high beads) were used to ensure the quality of the $\mathrm{CD} 4^{+} \mathrm{T}$ cell test.

\section{HIV viral load measurement}

HIV viral loads in plasma were detected by performing RT-PCR using the COBAS Amplicor HIV Monitor 1.5 (RocheMolecular Systems, Branchbury, NJ, USA) with a detection limit of between 400 copies $/ \mathrm{ml}$ and $7.5 \times 10^{5}$ copies $/ \mathrm{ml}$.

\section{Relative quantitative analysis of KIR mRNA expression}

RNA was isolated from peripheral blood mononuclear cells (PBMCs) using QIAamp RNA Mini Kits (Qiagen, Germany) and assayed for purity and concentration. Total RNA $(1 \mu \mathrm{g})$ was converted to cDNA using the Improm-II ${ }^{\mathrm{m}}$ Reverse Transcriptim System (Promege, USA). Specific primers for the KIR genes of interest were synthesized according to the reported method $[22,23]$. The glyceraldehyde-3-phosphate dehydrogenase (GADPH) gene was selected as a reference gene to control for different input RNA $[24,25]$. The primers (forward and reverse sequences) for the KIR3DS1 gene were 5' - CAGCGCTGTGGTGCCTCGC-3' and 5'-CTGTG ACCATGATCACCAT-3' [22], for the KIR3DL1 gene were 5'-GGACATCGTGGTCACAGGTCC-3' and 5'CACTGAGGTCCCAATCAGAATG-3' [25], for the GAPDH gene were, 5'-GGTGGTCTCCTCTGACTT CAACA-3' and ' 5'-GTTGCTGTAGCCAAATTCGTT GT-3'. The specificity of these primer sets was confirmed by PCR and DNA sequencing (done by BGI China). A plasmid DNA standard was first constructed.
Briefly, the KIR3DS1, KIR3DL1 and GADPH mRNAs were amplified by PCR from their respective cDNA fragments. The products were cloned into pMD 18-T vectors (Takara, Japan) The plasmid standard was serially diluted $\left(1: 10,1: 10^{2}, 1: 10^{3}, 1: 10^{4}, 1: 10^{5}\right)$ and used for PCR. Real-time quantitative PCR amplification was performed using SYBR Premix Ex Taq (Takara, Japan). Cycling conditions were: 1 initial cycle, 30 seconds at $95^{\circ} \mathrm{C}$; followed by 40 cycles, 30 seconds at $95^{\circ} \mathrm{C}$; and 1 final cycle, 34 seconds at $60^{\circ} \mathrm{C}$. To ensure specificity, dissociation curves were analyzed after each run. The relative expression of KIR mRNA was normalized to the expression of GAPDH in total RNA preparations.

\section{Statistical analysis}

Differences in KIR and HLA frequencies between the various study groups were assessed by using the $\mathrm{X}^{2}$ test for categorical variables. $\mathrm{P}$ values were calculated by using Yates's correction test or Fisher's exact test. KIR mRNA levels were compared between the groups by using non-parametric test analysis. Spearman's rank correlation was used to perform the correlation analysis. All analyses were carried out using SPSS 17.0 software. $P$ values $<0.05$ were considered significant.

\section{Results}

Relationship between the frequencies of KIR genes and HIV disease progression

We screened 14 KIR genes and two psuedogenes for each participant in our study. The frequencies of individuals positive for each gene among the whole study population were calculated and listed in Additional file 1: Table S1. In our study population, we found that two alleles in the KIR gene cluster (KIR3DL3 and KIR3DL2) were present in $100 \%$ of participants. The frequencies of individuals with the KIR2DL4 gene or the KIR3DP1 gene were also approximately $100 \%$ in our pariticipants.

Firstly, we examined the associations between various KIR genes and the maintenance of $\mathrm{CD}^{+} \mathrm{T}$ cell counts. We found that the frequency of individuals with KIR3DS1 gene was significantly higher in the "high $\mathrm{CD} 4^{+} \mathrm{T}$ cell count" group than in the "low $\mathrm{CD} 4^{+} \mathrm{T}$ cell count" group ( $44.9 \%$ vs. $26.5 \%, P=0.025$; Table 1$)$. However, the frequency of individuals with the KIR3DL1 gene was not different between the two groups $(P=0.266$; Table 1$)$. There were no statistical differences in the frequencies of individuals with other KIR genes between the "high $\mathrm{CD} 4^{+} \mathrm{T}$ cell count" group and the "low $\mathrm{CD}^{+} \mathrm{T}$ cell count" group (Table 1). In addition, we found that the KIR3DS1 allele frequency was higher in the "high $\mathrm{CD} 4^{+} \mathrm{T}$ cell count" group than in the "low $\mathrm{CD} 4^{+} \mathrm{T}$ cell count" group $(P=$ 0.02; Table 2). Conversely, the KIR3DL1 allele frequency was lower in the "high $\mathrm{CD} 4^{+} \mathrm{T}$ cell count" group than in the "low $\mathrm{CD} 4^{+} \mathrm{T}$ cell count" group $(P=0.02$; Table 2$)$. 
Table 1 Distribution of KIR gene frequency ${ }^{1}$ among individuals in different groups

\begin{tabular}{|c|c|c|c|c|c|c|c|c|c|}
\hline KIRgene & $\begin{array}{c}{ }^{2} \text { LowCD4 } \\
\text { (Total 83) } \\
\text { n (\%) }\end{array}$ & $\begin{array}{c}{ }^{3} \text { High CD4 } \\
\text { (Total 49) } \\
\text { n (\%) }\end{array}$ & $P$ & $\begin{array}{c}{ }^{4} \text { High VL } \\
\text { (Total 84) } \\
\text { n (\%) }\end{array}$ & $\begin{array}{c}{ }^{5} \text { Low VL } \\
\text { (Total 48) } \\
\text { n (\%) }\end{array}$ & $P$ & $\begin{array}{c}{ }^{6} \mathrm{TP} \\
\text { (Total 83) } \\
\text { n (\%) }\end{array}$ & $\begin{array}{c}{ }^{7} \text { LTNP } \\
\text { (Total 40) } \\
\text { n (\%) }\end{array}$ & $P$ \\
\hline KIR2DL1 & $80(96.4)$ & $47(95.9)$ & 0.615 & $81(96.4)$ & 46 (95.8) & 0.601 & $80(96.4)$ & $40(100.0)$ & 0.304 \\
\hline KIR2DL2 & $43(51.8)$ & $32(65.3)$ & 0.091 & $46(54.8)$ & $29(60.4)$ & 0.328 & $43(51.8)$ & $26(65.0)$ & 0.117 \\
\hline KIR2DL3 & 81 (97.6) & $46(93.9)$ & 0.266 & 82 (97.6) & 45 (93.8) & 0.253 & 81 (97.6) & $40(100.0)$ & 0.454 \\
\hline KIR2DL4 & $82(98.8)$ & $49(100.0)$ & 0.629 & 83 (98.8) & 47 (97.9) & 0.597 & 82 (98.8) & $40(100.0)$ & 0.675 \\
\hline KIR2DL5 & $35(42.2)$ & $22(44.9)$ & 0.450 & $36(42.9)$ & $21(43.8)$ & 0.532 & $35(42.2)$ & $18(45.0)$ & 0.458 \\
\hline KIR2DS1 & $34(41.0)$ & $26(53.1)$ & 0.122 & $36(42.9)$ & $24(50.0)$ & 0.270 & $34(41.0)$ & $21(52.5)$ & 0.156 \\
\hline KIR2DS2 & $23(27.7)$ & $12(24.5)$ & 0.424 & 19 (22.6) & $16(33.3)$ & 0.128 & $23(27.7)$ & $9(22.5)$ & 0.350 \\
\hline KIR2DS3 & $13(15.7)$ & $11(22.4)$ & 0.227 & 15 (17.9) & $9(18.8)$ & 0.537 & $13(15.7)$ & $11(27.5)$ & 0.097 \\
\hline KIR2DS4 & 81 (97.6) & $46(93.9)$ & 0.266 & $82(97.6)$ & 45 (93.8) & 0.253 & 81 (97.6) & $37(92.5)$ & 0.194 \\
\hline KIR2DS5 & $26(31.3)$ & 18 (36.7) & 0.326 & $27(32.1)$ & $17(35.4)$ & 0.422 & $26(31.3)$ & $14(35.0)$ & 0.417 \\
\hline KIR2DP1 & $80(96.4)$ & 47 (95.9) & 0.615 & 81 (96.4) & $46(95.8)$ & 0.601 & $80(96.4)$ & $40(100.0)$ & 0.304 \\
\hline KIR3DP1 & $83(100.0)$ & $48(98.0)$ & 0.371 & $84(100.0)$ & 47 (97.9) & 0.364 & $83(100.0)$ & 39 (97.5) & 0.325 \\
\hline KIR3DL1 & 81 (97.6) & 46 (93.9) & 0.266 & 82 (97.6) & 45 (93.8) & 0.253 & 81 (97.6) & $37(92.5)$ & 0.194 \\
\hline KIR3DL2 & $83(100.0)$ & $49(100.0)$ & & $84(100.0)$ & $48(100.0)$ & & $83(100.0)$ & $40(100.0)$ & \\
\hline KIR3DL3 & $83(100.0)$ & $49(100.0)$ & & $84(100.0)$ & $48(100.0)$ & & $83(100.0)$ & $40(100.0)$ & \\
\hline KIR3DS1 & $22(26.5)$ & $22(44.9)$ & 0.025 & $25(29.8)$ & 19 (39.6) & 0.169 & $22(26.5)$ & $18(45.0)$ & 0.033 \\
\hline
\end{tabular}

${ }^{1}$ The frequency of individuals with at least one copy of the $16 \mathrm{KIR}$ genes.

${ }^{2}$ Low CD4, "low CD4 ${ }^{+} \mathrm{T}$ cell count" group $\left(\mathrm{CD} 4^{+} \mathrm{T}\right.$ cell counts $\geq 500$ cells/ $\left.\mu \mathrm{l}\right) ;{ }^{3} \mathrm{High} \mathrm{CD} 4$, "High CD4 ${ }^{+} \mathrm{T}$ cell count" group $\left(\mathrm{CD} 4{ }^{+} \mathrm{T}\right.$ cell counts $\left.<500 \mathrm{cells} / \mu \mathrm{l}\right) ;{ }^{4} \mathrm{High} \mathrm{VL}$, "high viral load" group (HIV viral load $\geq 10^{4}$ copies/ml); ${ }^{5}$ Low VL, "low viral load" group (HIV viral load $<10^{4}$ copies/ml); ${ }^{6}$ TP, HIV typical progressors; ${ }^{7}$ LTNP, HIV long-term nonprogressors (9 individuals were excluded for the analysis based on LTNPs or TPs, because of not meeting the criteria of LTNPs or TPs). $\mathrm{n}$, the number of individuals with each KIR gene in each group; \%, the percentage of individuals with each KIR gene in each group. Data was calculated by from Yates's correction or Fisher's exact test. Bold numbers indicated $P$ value $<0.05$.

Then, we investigated the associations between the KIR genes and HIV viral loads. There were no significant differences in the frequencies of individuals with the KIR3DS1 gene or the KIR3DL1 gene between the "high viral load" group and the "low viral load" group $(29.8 \%$ vs. $39.6 \%$ for KIR3DS1, $P=0.169 ; 97.6 \%$ vs. $93.8 \%$ for KIR3DL1, $P=0.253$; Table 1$)$. In fact, there were no statistically significant differences in the frequencies of individuals with other KIR genes between the "low viral load" group and the "high viral load" group.

In addition to these results, we observed that the frequency of individuals with the KIR3DS1 gene was higher in LTNPs than in TPs $(45.0 \%$ vs. $26.5 \%, P=0.033$; Table 1). However, there was no statistical difference in the frequency of individuals with the KIR3DL1 gene between TPs and LTNPs $(97.6 \%$ vs. 92.5\%, $P=0.194$; Table 1). However, there were no statistical differences in the frequencies of individuals with other KIR genes between the LTNP group and the TP group either (Table 1). Additionally, we found that the KIR3DS1 allele frequency was higher in LTNPs than in TPs $(P=0.03$; Table 2), and the KIR3DL1 allele frequency was lower in LTNPs than in TPs $(P=0.03$; Table 2$)$.

Finally, we analyzed the differences between different groups in the KIR3DS1/L1 genotypes (KIR3DS1 homozygotes, KIR3DS1/L1 heterozygotes and KIR3DL1 homozygotes). We found that the frequency of KIR3DL1 homozygotes (KIR3DL1/L1) was higher in the"low CD4 $4^{+}$

Table 2 The allele frequency of KIR3DS1 or KIR3DL1 between different groups

\begin{tabular}{|c|c|c|c|c|c|c|c|c|c|}
\hline \multirow{2}{*}{$\begin{array}{l}\text { KIR } \\
\text { alleles }\end{array}$} & ${ }^{1}$ Low CD4 & ${ }^{2}$ High CD4 & \multirow[t]{2}{*}{$P$} & ${ }^{3}$ High VL & ${ }^{4}$ Low VL & \multirow[t]{2}{*}{$P$} & ${ }^{5} \mathrm{TP}$ & ${ }^{6}$ LTNP & \multirow[t]{2}{*}{$P$} \\
\hline & n/166 (\%) & n/98 (\%) & & n/168 (\%) & n/96 (\%) & & n/166 (\%) & n/80 (\%) & \\
\hline KIR3DL1 & $142 / 166(85.5)$ & 73/98 (74.5) & 0.02 & 141/168 (83.9) & 74/96 (77.1) & 0.11 & 142/166 (85.5) & $59 / 80(73.7)$ & 0.03 \\
\hline KIR3DS1 & 24/166 (14.5) & 25/98 (25.5) & 0.02 & 27/168 (16.1) & 22/96 (22.9) & 0.11 & $24 / 166(14.5)$ & $21 / 80(26.3)$ & 0.03 \\
\hline
\end{tabular}

Data are the frequencies of KIR alleles (assuming the pairs 3DS1/3DL1 are alleles of respective loci).

${ }^{1}$ Low CD4, "low CD4 ${ }^{+} \mathrm{T}$ cell count" group $\left(\mathrm{CD} 4^{+} \mathrm{T}\right.$ cell counts $<500$ cells $\left./ \mu \mathrm{l}\right){ }^{2}{ }^{2} \mathrm{High} \mathrm{CD} 4$, "High $\mathrm{CD} 4{ }^{+} \mathrm{T}$ cell count" group (CD4 ${ }^{+} \mathrm{T}$ cell counts $\geq 500$ cells/ $\left.\mu \mathrm{l}\right) ;{ }^{3} \mathrm{High} \mathrm{VL}$, "high viral load" group (HIV viral load $\geq 10^{4}$ copies/ml); ${ }^{4}$ Low VL, "low viral load" group (HIV viral load< $10^{4}$ copies/ml); ${ }^{5} \mathrm{TP}, \mathrm{HIV}$ typical progressors; ${ }^{6} \mathrm{LTNP}$, HIV longterm nonprogressors ( 9 individuals were excluded for the analysis based on LTNPs or TPs, because of not meeting the criteria of LTNPs or TPs). Data was calculated by from Yates's correction or Fisher's exact test.

Bold numbers indicate $P$ value $<0.05$. 
$\mathrm{T}$ cell count" group than in the "high $\mathrm{CD} 4^{+} \mathrm{T}$ cell count" group $(P=0.025$, Table 3$)$. Similarly, the frequency of the KIR3DL1 homozygotes in TPs was higher than in LTNPs $(P=0.033$, Table 3$)$. However, there was no difference between the "high viral load" group and the "low viral load" group. We didn't observe that the frequencies of KIR3DS1 homozygotes (KIR3DS1/S1) or KIR3DS1/L1 heterozygotes (KIR3DS1/L1) were different between groups (Table 3).

These data demonstrate that KIR3DS1 gene is associated with higher $\mathrm{CD} 4^{+} \mathrm{T}$ cell counts and might delay the disease progression.

Association of the HLA-B gene with HIV disease progression After analyzing the relationship between the KIR gene frequency and HIV disease progression, we subsequently divided our study participants according to their Bw4 or Bw6 epitopes, and analyzed the association between the HLA-B genes and HIV disease progression. We found that people with at least one copy of the HLA-Bw4-80I gene had higher $\mathrm{CD}_{4}^{+} \mathrm{T}$ cell counts $(P=0.015$; Figure $1 \mathrm{~A})$. The proportion of Bw4/Bw6 heterozygous individuals with Bw4-80I was much higher in the "high $\mathrm{CD} 4^{+} \mathrm{T}$ cell count" group than in the "low $\mathrm{CD} 4^{+} \mathrm{T}$ cell count" group $(P=$ 0.006; Figure 1A). However, we did not find any statistical differences in HLA-B gene frequencies between the "high viral load" group and the "low viral load" group $(P>0.05$; Figure $1 \mathrm{~B})$. We found that the proportion of people who had at least one copy of HLA-Bw4-80I was higher among LTNPs $(P=0.006$; Figure $1 C)$. Moreover, the proportion of Bw4/Bw6 heterozygous individuals with Bw4-80I was also

Table 3 Genotypic distribution of 3DS1/3DL1 and the ligand among individuals in different groups

\begin{tabular}{|c|c|c|c|c|c|c|c|c|c|}
\hline Allele genotype, ligand & $\begin{array}{c}{ }^{1} \text { Low CD4 } \\
\text { (Total 83) } \\
\text { n (\%) }\end{array}$ & $\begin{array}{c}{ }^{2} \text { High CD4 } \\
\text { (Total 49) } \\
\text { n (\%) }\end{array}$ & $P$ & $\begin{array}{c}{ }^{3} \text { High VL } \\
\text { (Total 84) } \\
\text { n (\%) }\end{array}$ & $\begin{array}{c}{ }^{4} \text { Low VL } \\
\text { (Total 48) } \\
\text { n (\%) }\end{array}$ & $P$ & $\begin{array}{c}{ }^{5} \mathrm{TP} \\
\text { (Total 83) } \\
\text { n (\%) }\end{array}$ & $\begin{array}{c}{ }^{6} \text { LTNP } \\
\text { (Total 40) } \\
\text { n (\%) }\end{array}$ & $P$ \\
\hline 3DS1/3DL1 & $20(24.1)$ & $19(38.8)$ & 0.057 & $23(27.4)$ & $16(33.3)$ & 0.299 & $20(24.1)$ & $15(37.5)$ & 0.093 \\
\hline 3DS1/3DS1 & $2(2.4)$ & $3(6.1)$ & 0.266 & $2(2.4)$ & $3(6.3)$ & 0.253 & $2(2.4)$ & $3(7.5)$ & 0.194 \\
\hline 3DL1/3DL1 & $61(73.5)$ & $27(55.1)$ & 0.025 & $59(70.2)$ & $29(60.4)$ & 0.169 & $61(73.5)$ & $22(55.0)$ & 0.033 \\
\hline 3DS1/?, with 80 l & $2(2.4)$ & $9(18.4)$ & 0.002 & $7(8.3)$ & $4(8.3)$ & 0.636 & $2(2.4)$ & $9(22.5)$ & 0.001 \\
\hline 3DL1/?, with 80 l & $11(13.3)$ & $15(30.6)$ & 0.015 & $13(15.5)$ & $13(27.1)$ & 0.084 & $11(13.3)$ & $14(35.0)$ & 0.006 \\
\hline 3DS1/3DS1, with 80l & $0(0.0)$ & $0(0.0)$ & & $0(0.0)$ & $0(0.0)$ & & $0(0.0)$ & $0(0.0)$ & \\
\hline 3DL1/3DL1, with 80I & $9(10.8)$ & $6(12.2)$ & 0.508 & $6(7.1)$ & $9(18.8)$ & 0.043 & $9(10.8)$ & $5(12.5)$ & 0.501 \\
\hline 3DS1/3DL1, with 80l & $2(2.4)$ & $9(18.4)$ & 0.002 & $7(8.3)$ & $4(8.3)$ & 0.636 & $2(2.4)$ & $9(22.5)$ & 0.001 \\
\hline 3DS1/?, no 801 & $20(24.1)$ & $13(26.5)$ & 0.455 & $18(21.4)$ & $15(31.2)$ & 0.148 & $20(24.1)$ & $9(22.5)$ & 0.518 \\
\hline 3DL1/?, no 801 & $70(84.3)$ & $31(63.3)$ & 0.006 & $69(82.1)$ & $32(66.7)$ & 0.037 & $70(84.3)$ & $23(57.5)$ & 0.002 \\
\hline 3DS1/3DS1, no 80l & $2(2.4)$ & $3(6.1)$ & 0.266 & $2(2.4)$ & $3(6.3)$ & 0.253 & $2(2.4)$ & $3(7.5)$ & 0.194 \\
\hline 3DL1/3DL1, no 80I & $52(62.7)$ & $21(42.9)$ & 0.021 & $53(63.1)$ & $20(41.7)$ & 0.014 & $52(62.7)$ & $17(42.5)$ & 0.028 \\
\hline 3DS1/3DL1, no 80I & $18(21.7)$ & $10(20.4)$ & 0.523 & $16(19.1)$ & $12(25.0)$ & 0.277 & $18(21.7)$ & $6(15.0)$ & 0.267 \\
\hline 3DS1/?, with $80 \mathrm{~T}$ & $1(1.2)$ & $0(0.0)$ & 0.629 & $1(1.2)$ & $0(0.0)$ & 0.636 & $1(1.2)$ & $0(0.0)$ & 0.675 \\
\hline 3DL1/?, with $80 \mathrm{~T}$ & $7(8.4)$ & $1(2.0)$ & 0.132 & $5(6.0)$ & $3(6.3)$ & 0.609 & $7(8.4)$ & $1(2.5)$ & 0.2 \\
\hline 3DL1/3DL1, with $80 \mathrm{~T}$ & $6(7.2)$ & $1(2.0)$ & 0.192 & $4(4.8)$ & $3(6.3)$ & 0.501 & $6(7.2)$ & $1(2.5)$ & 0.271 \\
\hline 3DS1/3DL1, with $80 \mathrm{~T}$ & $1(1.2)$ & $0(0.0)$ & 0.629 & $1(1.2)$ & $0(0.0)$ & 0.636 & $1(1.2)$ & $0(0.0)$ & 0.675 \\
\hline 3DS1/3DS1, with $80 \mathrm{~T}$ & $0(0.0)$ & $0(0.0)$ & & $0(0.0)$ & $0(0.0)$ & & $0(0.0)$ & $0(0.0)$ & \\
\hline 3DS1/?, no $80 T$ & $21(25.3)$ & $22(44.9)$ & 0.017 & $24(28.6)$ & $19(39.6)$ & 0.135 & $21(25.3)$ & $18(45.0)$ & 0.024 \\
\hline 3DL1/?, no $80 T$ & $74(89.2)$ & $45(91.8)$ & 0.431 & $77(91.7)$ & $42(87.5)$ & 0.314 & $74(89.2)$ & $36(90.0)$ & 0.579 \\
\hline 3DL1/3DL1, no $80 T$ & $55(66.3)$ & $26(53.1)$ & 0.094 & $55(65.5)$ & $26(54.2)$ & 0.136 & $55(66.3)$ & $21(52.5)$ & 0.102 \\
\hline 3DS1/3DL1, no $80 \mathrm{~T}$ & 19 (22.9) & $19(53.1)$ & 0.041 & $22(26.2)$ & $16(33.3)$ & 0.25 & $19(22.9)$ & $15(37.5)$ & 0.071 \\
\hline 3DS1/3DS1, no $80 T$ & $2(2.4)$ & $3(6.1)$ & 0.266 & $2(2.4)$ & $3(6.3)$ & 0.253 & $2(2.4)$ & $3(7.5)$ & 0.194 \\
\hline
\end{tabular}

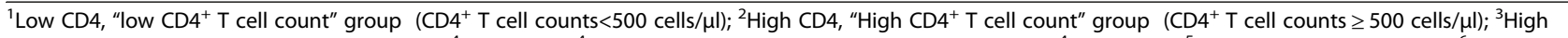
VL, "high viral load" group (HIV viral load $\geq 10^{4}$ copies/ml); ${ }^{4}$ Low VL, "low viral load" group (HIV viral load $<10^{4}$ copies/ml); ${ }^{5}$ TP, HIV typical progressors; ${ }^{6} \mathrm{LTNP}, \mathrm{HIV}$ long-term nonprogressors (9 individuals were excluded for the analysis based on LTNPs or TPs, because of not meeting the criterions of LTNPs or TPs). 3DS1/L1, KIR3DS1/L1 heterozygotes; 3DS1/S1, 3DS1 homozygotes; 3DL1/L1, KIR3DL1 homozygotes.

3DS1/?, individuals with at least one copy of KIR3DS1 gene; 3DL1/?, individuals with at least one copy of KIR3DL1 gene.

80I, HLA-Bw4-80l; 80 T, HLA-Bw4-80 T.

$\mathrm{n}$, the number of individuals with each genotype in each group; \%, the percentage of individuals with each genotype in each group Data was calculated by from Yates's correction or Fisher's exact test.

Bold numbers indicate $P$ value $<0.05$. 


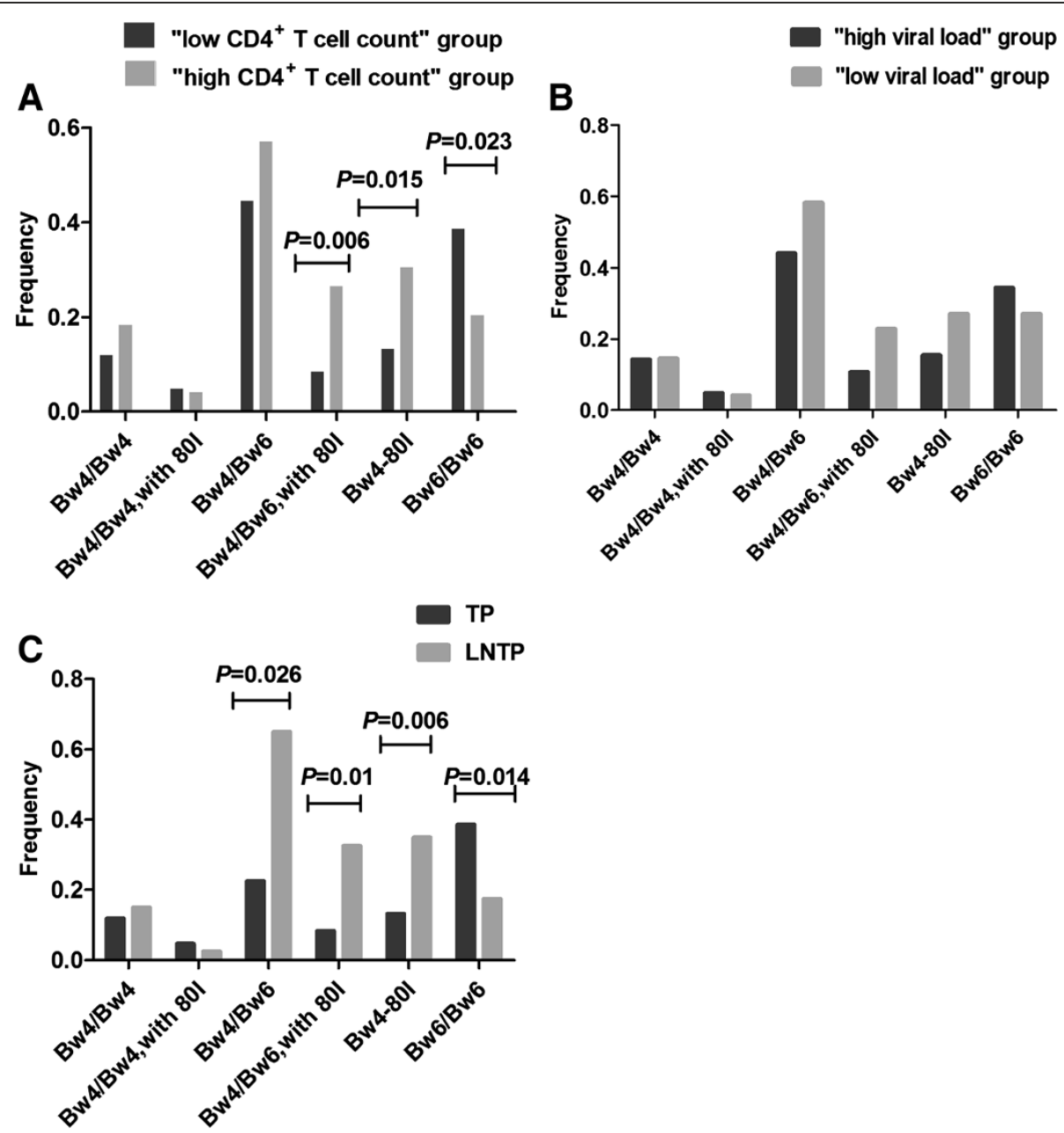

Figure 1 Association of HLA-B gene with HIV disease progression. Shown are results for the comparisons of the frequency of individuals in various study groups carrying a particular gene. (A) HLA-B gene frequencies among the "high CD4 ${ }^{+} \mathrm{T}$ cell count" group (light grey) and the "low $\mathrm{CD}^{+} \mathrm{T}$ cell count" group (dark grey) are shown. The data show that subjects who had at least one copy of the HLA-Bw4-80l gene had higher $\mathrm{CD}^{+} \mathrm{T}$ cell counts $(P=0.015)$. However, HLA-Bw6 homozygotes had lower CD4 ${ }^{+} \mathrm{T}$ cell counts $(P=0.023)$. (B) HLA-B gene frequencies among the "high viral load" group (light grey) and the "low viral load" group (dark grey) are shown. (C) HLA-B allele frequencies among TPs (light grey) and LTNPs (dark grey) are shown. The data show that the proportion of people who had at least one copy of the HLA-Bw4-80l gene was higher among LTNPs than among TPS $(P=0.006)$. However, the proportion of HLA-Bw6 homozygotes was significantly lower among LTNPs than among $\operatorname{TPs}(P=0.014)$.

significantly higher among LTNPs, as compared with TPs $(P=0.001$; Figure 1C). Furthermore, we found that the proportion of HLA-Bw6 homozygotes was significantly lower among LTNPs $(P=0.014$; Figure $1 C)$.

Our results indicate that HLA-Bw4-80I might be associated with slower disease progression and HIV-infected individuals who are homozygous for HLA-Bw6 might experience faster disease progression.

\section{Association of the combination of KIR3DS1/3DL1 and HLA-Bw4-80I genes with disease progression}

We were interested in determining whether the combination of the KIR3DS1/L1 genotype and the HLA-Bw4-80I gene had any association with HIV disease progression.
Firstly, we analyzed the frequency of individuals with the KIR3DS1/L1 genotype and HLA-Bw4-80I gene among TPs and LTNPs. We found that the frequency of individuals with at least one copy of KIR3DS1 in the presence of HLA-Bw4 -80I (3DS1/?, with 80I; Table 3) was notably higher in LTNPs than in TPs $(P=0.001$; Table 3$)$, and the frequency of KIR3DS1/L1 heterozygotes with HLA-Bw4-80I (3DS1/ L1, with 80I; Table 3) was also higher in LTNPs than in TPs $(P=0.001$; Table 3). Meanwhile, we also found that the frequency of individuals with at least one copy of KIR3DL1 in the presence of HLA-Bw4-80I (3DL1/?, with 80I; Table 3) was higher in LTNPs than in TPs $(P=0.006$; Table 3$)$, and conversely, the frequency of individuals with at least one copy of KIR3DL1 in absence of HLA-Bw4-80I (3DL1/?, no 
80I; Table 3) was lower in LTNPs than in TPs $(P=0.002$; Table 3). Moreover, the frequency of KIR3DL1 homozygotes without HLA-Bw4-80I (3DL1/L1, no 80I; Table 3) was much lower in LTNPs than in TPs $(P=0.028$; Table 3$)$.

Given that the combination of the KIR3DS1/3DL1 and HLA-Bw4-80I genes might be predictive of a patient's ability to manage HIV replication and $\mathrm{CD} 4^{+} \mathrm{T}$ cell counts, we subsequently analyzed the association between the genotypes and HIV viral loads or $\mathrm{CD}^{+}{ }^{+} \mathrm{T}$ cell counts. We found that the frequencies of individuals with at least one copy of KIR3DS1 in the presence of HLA-Bw4-80I (3DS1/?, with 80I; Table 3) was more common in the "high $\mathrm{CD} 4^{+} \mathrm{T}$ cell count" group than in the "low $\mathrm{CD} 4^{+} \mathrm{T}$ cell count" group $(P=0.002$; Table 3$)$. In addition, the frequency of individuals with at least one copy of KIR3DL1 in the presence of HLA-Bw4-80I (3DL1/?, with 80I; Table 3) was also more common in the "high $\mathrm{CD} 4^{+} \mathrm{T}$ cell count" group than in the "low $\mathrm{CD}^{+}{ }^{+} \mathrm{T}$ cell count" group $(P=0.015$; Table 3$)$. However, we observed that the individuals with at least one copy of KIR3DL1in absence of HLA-Bw4-80I (3DL1/?, no 80I ) had lower $\mathrm{CD}^{+} \mathrm{T}$ cell counts and higher HIV viral loads $(P=0.006$ and $P=0.037$, respectively; Table 3$)$. Similarly, KIR3DL1/L1 homozygotes without HLA-Bw480I (3DL1/L1, no 80I) also had lower CD4 $4^{+} \mathrm{T}$ cell counts and higher HIV viral loads $(P=0.021$ and $P=0.014$, respectively; Table 3).

Our analyses above were based on categorizations of $\mathrm{CD} 4^{+} \mathrm{T}$ cell counts, HIV viral loads and disease progression to compare the frequency of subjects with positive genes or alleles. The next analyses compared $\mathrm{CD}^{+} \mathrm{T}$ cell counts and HIV viral loads between different three groups classified as $3 \mathrm{DS}^{+} 80 \mathrm{I}^{+}$, $3 \mathrm{DS} 1^{+} 80 \mathrm{I}^{-}$and the $3 \mathrm{DS} 1^{-} 80 \mathrm{I}^{+}$. The individuals with at least one copy of KIR3DS1 in presence of HLA-Bw4-80I were in the "3DS1 ${ }^{+} 80 \mathrm{I}^{+}$" group. The individuals with at least one copy of KIR3DS1 in absence of HLABw4-80I were in the "3DS1 $1^{+} 80 \mathrm{I}^{\text {" }}$ group, and KIR3DL1 homozygotes with HLA-Bw4-80I were in the "3DS1" $80 \mathrm{I}^{+"}$ group. We found that $\mathrm{CD} 4^{+} \mathrm{T}$ cell counts were much higher in the " $3 \mathrm{DS}^{+} 80 \mathrm{I}^{+}$" group than in the " $3 \mathrm{DS} 1^{+} 80 \mathrm{I}^{-}$" group $(P=0.041)$. However, there was no significant difference between the $\mathrm{CD} 4^{+} \mathrm{T}$ cell counts of the " $3 \mathrm{DS} 1^{+} 80 \mathrm{I}^{+}$" group and the "3DS1 $80 \mathrm{I}^{+}$" group $(P=0.312)$. We didn't find any statistical difference between the viral loads of the "3DS1 ${ }^{+} 80 \mathrm{I}^{+}$" group and the "3DS1 $1^{+} 80 \mathrm{I}^{-}$" group $(P=0.524)$. Neither was there a significant difference between the viral loads of the " $3 \mathrm{DS}^{+} 80 \mathrm{I}^{+}$" group and the " $3 \mathrm{DS1}^{-} 80 \mathrm{I}^{+"}$ group $(P=0.087)$ (data not shown). Altogether, these results demonstrate that the KIR3DS1 and HLA-Bw4-80I combined genotype is associated with slow HIV disease progression and higher $\mathrm{CD} 4^{+} \mathrm{T}$ cell counts.

In addition, we also analyzed the combination of KIR3DS1/L1 with or without HLA-Bw4-80 T among the different groups. There were no between group differences in the frequency of the KIR3DS1/L1 with HLA-Bw4-80 T combined genotype for comparisons based on $\mathrm{CD}^{+} \mathrm{T}$ cell counts, HIV viral load or disease progression. The frequency of individuals with at least one copy of KIR3DS1 in the absence of HLA-Bw4-80 T (3DS1/?, no $80 \mathrm{~T}$; Table 3) was higher in LTNPs compared to TPs $(P=0.024$; Table 3$)$, and higher in the "high $\mathrm{CD}^{+} \mathrm{T}$ cell count" group compared to the "low $\mathrm{CD}_{4}^{+} \mathrm{T}$ cell count" group $(P=0.017$; Table 3). We also found that the KIR3DS1/L1 heterozygotes without HLA-Bw4-80 T (3DS1/L1, no $80 \mathrm{~T}$ ) was higher in the "high $\mathrm{CD} 4^{+} \mathrm{T}$ cell count" group compared to the "low $\mathrm{CD}^{+}{ }^{+} \mathrm{T}$ cell count" group $(P=0.041$; Table 3$)$.

\section{KIR3DS1 and KIR3DL1 mRNA levels are associated with HIV disease progression}

Our data suggest that the KIR3DS1/3DL1 gene is associated with HIV disease progression. To determine whether levels of KIR3DS1/KIR3DL1 mRNA impact HIV disease progression, we carried out relative quantitative analysis of KIR mRNA expression to compare the transcript levels of the KIR3DS1/KIR3DL1 gene among different groups. We observed that the KIR3DS1 mRNA levels were significantly higher in the "high $\mathrm{CD}^{+}{ }^{+} \mathrm{T}$ cell count" group, the LNTP group, and the "low viral load" group $(P=0.01, P=0.003$ and $P=0.006$, respectively; Figure $2 \mathrm{~A}, 2 \mathrm{~B}$ and $2 \mathrm{C}$ ). Thus, these results suggest that individuals who have more KIR3DS1 mRNA may experience slower HIV disease progression.

We found different results regarding KIR3DL1, whose mRNA levels were significantly lower in the "high $\mathrm{CD} 4^{+}$ $\mathrm{T}$ cell count" group than in the "low $\mathrm{CD} 4^{+} \mathrm{T}$ cell count" group $(P=0.041$; Figure $2 \mathrm{D})$. However, we found no significant difference between KIR3DL1 mRNA levels in the "low viral load" group and the "high viral load" group $(P=0.067$; Figure $2 \mathrm{E})$, but the mRNA levels were lower among LTNPs than among TPs $(P=0.023$; Figure 2F). Together, these results indicate that mRNA levels of the KIR3DL1 gene in HIV-infected individuals may be associated with disease progression.

\section{Correlation between KIR3DS1 mRNA levels and $\mathrm{CD}^{+} \mathrm{T}$ cell counts or viral loads in HIV-infected individuals}

Our results show that KIR3DS1 mRNA levels are positively correlated with $\mathrm{CD} 4^{+} \mathrm{T}$ cell counts $(P=0.022, \mathrm{r}=$ 0.431; Figure $3 \mathrm{~A}$ ). This correlation indicates that individuals who have higher transcript quantities of KIR3DS1 have higher $\mathrm{CD} 4^{+} \mathrm{T}$ cell counts. However, there was no correlation between KIR3DS1 mRNA levels and viral loads $(P=0.12, \mathrm{r}=-0.3$; Figure $3 \mathrm{~B})$.

\section{Discussion}

The KIR gene cluster codes for ligands of HLA class I molecules. Population-level data suggest the co-evolution of KIR and HLA gene clusters, which are functionally related but unlinked. However, the KIR genes evolve more 

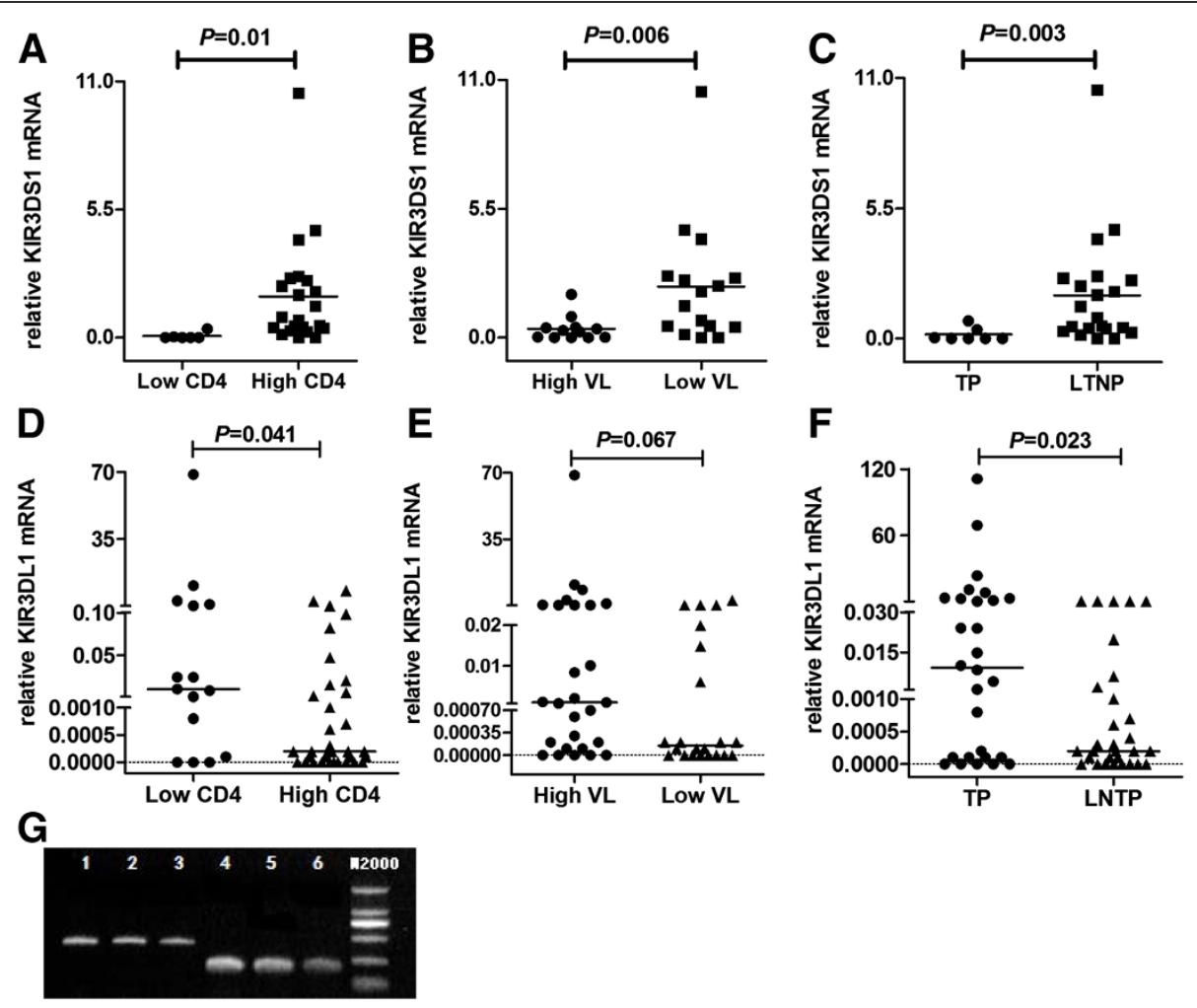

Figure 2 KIR3DS1 and KIR3DL1 mRNA levels of different groups. Shown are KIR transcript levels reflecting the relative expression of KIR3DS1 and KIR3DL1 mRNA normalized to GAPDH mRNA in total RNA preparations. Reported values are ratios of KIR and GAPDH concentrations. The lines denoted the medians. (A) KIR3DS1 mRNA levels of the "high $\mathrm{CD}^{+} \mathrm{T}$ cell count" group experienced a significant increase compared to KIR3DS1 mRNA levels in the "Iow CD4 ${ }^{+} T$ cell count" group $(P=0.01)$. (B) KIR3DS1 mRNA levels of the "high viral load" group experienced a significant decrease compared to those in the "low viral load" group $(P=0.006)$. (C) Levels of KIR3DS1 mRNA in TPs were significantly lower than in LTNPs $(P=0.003)$. (D) KIR3DL1 mRNA levels in the "high CD4 ${ }^{+} T$ cell count" group experienced a significant decrease compared to those in the "low CD4 ${ }^{+} T$ cell count" group $(P=0.041)$. (E) There was no statistical difference between levels of KIR3DL1 mRNA in the "high viral load" group and the "low viral load" group $(P=0.067)$. (F) KIR3DL1 mRNA levels of TPs were significantly higher than those of LTNPs $(P=0.023)$. (G) The electrophoretogram was shown to demonstrate the RT-PCR specificity. The PCR reaction only generates a single band. Lane 1, 2 and 3 were for KIR3DL1, and lane 4, 5 and 6 were for KIR3DS1 using different primer concentration.

rapidly than the HLA class I ligands [23]. Thus, we focused more on the association between the two gene clusters and HIV disease progression. By joint analysis of the two gene clusters together with HIV disease progression, we attempted to understand why some HIV-infected
Chinese experienced fast disease progression while others experienced slow disease progression.

In our study, we observed that KIR3DS1 was associated with slower HIV disease progression in LTNPs and with the maintenance of $\mathrm{CD} 4^{+} \mathrm{T}$ cell counts. Other
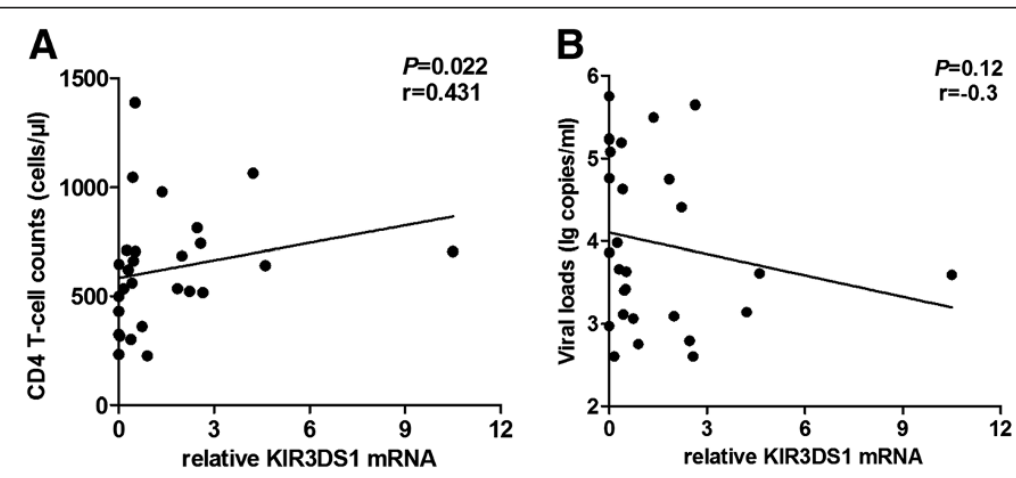

Figure 3 Correlation between KIR3DS1 mRNA levels and CD4 ${ }^{+} \mathrm{T}$ cell counts and viral loads among HIV infected individuals. (A) KIR3DS1 mRNA levels positively correlated with $C D 4^{+} T$ cell counts $(P=0.022, r=0.431)$. (B) KIR3DS1 mRNA levels and viral loads shared no correlation $(P=0.12, r=-0.3)$. $P$-values $<0.05$ were considered statistically significant. 
reports have also shown that KIR3DS1 independently associates with higher $\mathrm{CD} 4^{+} \mathrm{T}$ cell counts but does not have an effect on viral loads [12]. We speculated that KIR3DS1 might be associated with high NK cell function and result in slower disease progression. One study reported that NK cells in individuals who have the KIR3DS1 ${ }^{+}$allele produced more Interferon- $\gamma$ (IFN- $\gamma$ ) compared to NK cells in individuals without KIR3DS1 [26]. Several studies also reported that activated human NK cells could enhance the function of $\mathrm{CD}^{+} \mathrm{T}$ cells and promote differentiation of Th1 cells by secreting IFN- $\gamma$ [27]. Thus, we speculated that KIR3DS1, as an activating receptor, might enhance NK cell activity and help maintain the number of $\mathrm{CD} 4^{+} \mathrm{T}$ cells.

HLA-Bw4-80I, the ligand for the KIR3DL1 receptor and the putative ligand for the KIR3DS1 receptor, has been reported to be associated with HIV disease progression. Flores-Villanueva, et al. reported that, among Caucasians, homozygosity for HLA-Bw4 was strongly and independently associated with the ability to remain AIDS-free and maintain normal CD4 ${ }^{+} \mathrm{T}$ cell counts [28]. However, their analysis was specific to TPs and did not cover LTNPs. Conversely, in our study, we analyzed Chinese TPs and LTNPs. Our results showed that the proportion of HLA-Bw4 homozygotes is quite low among the Chinese population so there was no statistically significant difference in the frequency between LTNPs and TPs. But the frequency of heterozygosity for Bw4/Bw6 was much higher in LTNPs than in TPs. We also found that individuals who had at least one copy of HLA-Bw4-80I had higher $\mathrm{CD}^{+}{ }^{+} \mathrm{T}$ counts and slower disease progression and tended to have lower HIV viral loads. The potential benefit of the HLA-Bw4 allele was related to the specificity of this ligand for NK cell inhibitory receptor KIR3DL1 [29]. The presentation of HIV antigens by HLA-Bw4 alleles might relieve the inhibition of NK activity, resulting in enhanced lysis of infected cells by NK cells, which could thereby influence HIV viremia and the subsequent progression towards AIDS [28-30]. Meanwhile, HLA-Bw4 might have greater binding affinity for the HIV antigen and induce a more effective immune response than HLA-Bw6 alleles [26]. In agreement with other studies [31], we also observed that HLA-Bw6 homozygosity was associated with rapid disease progression. In this study, we also analyzed the association between the combination of the KIR3DS1/ KIR3DL1 and HLA-Bw4-80I genes with HIV disease progression. We found that KIR3DS1 together with HLA-Bw4-80I contribute to slower disease progression. We also observed that the absence of KIR3DS1 and HLA-Bw4-80I was associated with lower $\mathrm{CD}^{+}{ }^{+} \mathrm{T}$ cell counts and higher viral loads. The mechanism of how this genetic combination affects HIV disease progression remains unclear $[17,32]$. HLA-B*57 is associated with slow disease progression and viral load control [14]. We did not find any subject with this allele in our study. Therefore, the association of KIR3DS1 and HLA-Bw4 -80I with HIV disease course was not due to the influence HLA-B*57 may have on disease course in our study. KIR3DS1 activation might enhance NK cell activity and improved immune response. Recently, one functional association study reported that NK cells that were $\mathrm{KIR} \mathrm{DS} 1^{+}$inhibited HIV replication in HLA-Bw4-80I ${ }^{+}$ $\mathrm{T}$ cells [11]. These findings are consistent with our results at the functional level.

Conversely, we found that KIR3DL1 interaction with HLA-Bw4-80I was associated with slower $\mathrm{CD}^{+} \mathrm{T}$ cell count decline. The reason might be that the presence of both the inhibitory receptor KIR3DL1 and its HLA class I ligand HLA-Bw4-80I enhances NK cell responsiveness through a process known as NK cell "education" [33,34]. It seems that KIR3DL1 ${ }^{+} \mathrm{NK}$ cells exhibit a stronger response in the destruction of autologous HIV-infected cells when the inhibitory receptors are not bound to their ligands compared with KIR3DL1 ${ }^{-}$NK cells [35].

At the DNA level, we observed the association between KIR genes, especially KIR3DS1 and KIR3DL1, and HIV disease progression. We also identified an association between HIV disease progression and the levels of KIR3DS1/KIR3DL1 mRNA transcripts. Few studies were found related to quantitative mRNA expressions of the KIR gene cluster in HIV-infected individuals. Bostik, P. et al., reported that high levels of simian immunodeficiency virus (SIV) replication were associated with significant increases in KIR3DL1 mRNA levels among SIVinfected rhesus macaques [21]. Alter, G. et al. noted that levels of mRNA transcripts from activating KIRs were elevated in acute HIV infection and that levels of mRNA transcripts from inhibitory KIRs were elevated in chronic HIV infection [24]. In this study, we investigated the association between the mRNA expressions of KIR3DS1 or KIR3DL1 and HIV disease progression. We noted that individuals who had higher levels of KIR3DS1 mRNA had higher $\mathrm{CD}^{+}{ }^{+} \mathrm{T}$ cell counts and lower viral loads. Conversely, those expressing more KIR3DL1 mRNA had faster disease progression and lower $\mathrm{CD} 4^{+} \mathrm{T}$ cell counts. It should be pointed out that one of the limitations of the results presented in this study is that although multiple analyses were conducted none were subjected to a Bonferonni correction.

\section{Conclusions}

We demonstrated that the KIR3DS1 and KIR3DL1 gene with HLA-Bw4-80I gene have an association with the maintenance of $\mathrm{CD} 4^{+} \mathrm{T}$ cell count and slowing HIV disease progression. Our study also confirmed that homozygosity for the HLA-Bw6 allele was associated with rapid disease progression. We observed that high 
expression of KIR3DS1 mRNA was associated with slower disease progression, and high expression of KIR3DL1 mRNA was associated with rapid disease progression.

\section{Additional file}

Additional file 1: Table S1. KIR genotypes, $\mathrm{HLA}$ genotypes, $C D 4^{+} \mathrm{T}$ cell counts and viral loads of study population. The table reports the genotypes and frequencies of KIR genes, HLA genotypes, CD4 ${ }^{+} \mathrm{T}$ cell counts and viral loads among our study population.

\section{Abbreviations}

NK cells: Natural killer cells; KIR: Killer immunoglobulin-like receptor; KIR3DL1: Killer immunoglobulin-like receptor, three domains, long cytoplasmic tail 1; KIR3DS1: Killer immunoglobulin-like receptor, three domains, short cytoplasmic tail 1; HLA: Human leukocyte antigen; HIV: Human Immunodeficiency Virus; AIDS: Acquired immune deficiency syndrome; LTNP: Long-term nonprogressor; TP: Typical progressor.

\section{Competing interests}

The authors declare that they have no competing interests.

\section{Authors' contributions}

YJ designed the experiments, analyzed the data and wrote the manuscript. YJ and OC carried out part of KIR genotyping and participated in the analysis of nucleotides and amino acids of HLA-B. CC and CL carried out part of KIR genotyping and drafted the manuscript. BZ carried out HLA-B genotyping and participated in the analysis of nucleotides and amino acids of HLA-B. XH participated in HIV viral load measurement. YJ and ZZ carried out determination of $\mathrm{CD}^{+}{ }^{+} \mathrm{T}$ cell counts. $J \mathrm{~L}, \mathrm{JX}$ and $\mathrm{QH}$ were the clinical doctors who helped subject recruitment and carried out the epidemiological study. HS designed the study with YJ, verified and helped with interpretation of the data, and contributed to the writing. All authors read and approved the final manuscript.

\section{Acknowledgments}

The authors wish to express their gratitude to the patients who participated in this study. This work was supported by research grants from the Mega Projects of National Science Research for the 12th Five-year Plan (2012ZX10001-006), Liaoning Province Department of Higher Education Program for Excellence in Research (LR2012027), and the Program of the innovative group of institution of higher education by the Education Department of Liaoning Province (2009 T101).

\section{Author details}

${ }^{1}$ Key Laboratory of AIDS Immunology of Ministry of Health, Department of Laboratory Medicine, The First Affiliated Hospital, China Medical University, Shenyang 110001, P. R. China. ${ }^{2}$ Collaborative Innovation Center for Diagnosis and Treatment of Infectious Diseases, Hangzhou, China. ${ }^{3}$ Department of Laboratory Medicine, The Fourth Affiliated Hospital, China Medical University, Shenyang 110032, P. R. China.

\section{Received: 12 April 2013 Accepted: 30 August 2013}

Published: 2 September 2013

\section{References}

1. Jamil KM, Khakoo SI: KIR/HLA interactions and pathogen immunity. J Biomed Biotechnol 2011, 2011:1-9.

2. Yokoyama WM, Plougastel BFM: Immune functions encoded by the natural killer gene complex. Nat Rev Immunol 2003, 3(4):304-316.

3. Kulkarni S, Martin MP, Carrington M: The Yin and yang of HLA and KIR in human disease. Semin Immunol 2008, 20(6):343-352.

4. Boyton RJ, Altmann DM: Natural killer cells, killer immunoglobulin-like receptors and human leucocyte antigen class I in disease. Clin Exp Immunol 2007, 149(1):1-8.

5. Parham P: MHC class I molecules and kirs in human history, health and survival. Nat Rev Immunol 2005, 5(3):201-214.
6. Pascal V, Yamada E, Martin MP, Alter G, Altfeld M, Metcalf JA, Baseler MW, Adelsberger JW, Carrington M, Anderson SK, et al: Detection of KIR3DS1 on the cell surface of peripheral blood NK cells facilitates identification of a novel null allele and assessment of KIR3DS1 expression during HIV-1 infection. J Immunol 2007, 179(3):1625-1633.

7. Pelak K, Need AC, Fellay J, Shianna KV, Feng S, Urban TJ, Ge D, De Luca A, Martinez-Picado J, Wolinsky SM, et al: Copy number variation of KIR genes influences HIV-1 control. PLOS Biol 2011, 9(11):e1001208.

8. Parham P: MHC class I molecules and KIRs in human history, health and survival. Nat Rev Immunol 2005, 5(3):201-214.

9. Martin MP, Gao X, Lee JH, Nelson GW, Detels R, Goedert JJ, Buchbinder S, Hoots K, Vlahov D, Trowsdale J, et al: Epistatic interaction between KIR3DS1 and HLA-B delays the progression to AIDS. Nat Genet 2002, 31(4):429-434.

10. Qi Y, Martin MP, Gao X, Jacobson L, Goedert JJ, Buchbinder S, Kirk GD, O'Brien SJ, Trowsdale J, Carrington M: KIR/HLA pleiotropism: protection against both HIV and opportunistic infections. PLoS Pathog 2006, 2(8):e79.

11. Alter G, Martin MP, Teigen N, Carr WH, Suscovich TJ, Schneidewind A, Streeck $H$, Waring M, Meier A, Brander C, et al: Differential natural killer cell-mediated inhibition of HIV-1 replication based on distinct KIR/HLA subtypes. J Exp Med 2007, 204(12):3027-3036.

12. Barbour JD, Sriram U, Caillier SJ, Levy JA, Hecht FM, Oksenberg JR: Synergy or independence? deciphering the interaction of HLA class I and NK cell KIR alleles in early HIV-1 disease progression. PLoS Pathog 2007, 3(4):e43.

13. Gaudieri S, DeSantis D, McKinnon E, Moore C, Nolan D, Witt CS, Mallal SA, Christiansen FT: Killer immunoglobulin-like receptors and HLA act both independently and synergistically to modify HIV disease progression. Genes Immun 2005, 6(8):683-690.

14. Migueles SA, Sabbaghian MS, Shupert WL, Bettinotti MP, Marincola FM, Martino L, Hallahan CW, Selig SM, Schwartz D, Sullivan J, et al: HLA B*5701 is highly associated with restriction of virus replication in a subgroup of HIV-infected long term nonprogressors. Proc Natl Acad Sci U S A 2000 97(6):2709-2714.

15. Carr WH, Pando MJ, Parham P: KIR3DL1 Polymorphisms that affect NK cell inhibition by HLA-Bw4 ligand. J Immunol 2005, 175(8):5222-5229.

16. Lopez-Vazquez A, Mina-Blanco A, Martinez-Borra J, Njobvu PD, SuarezAlvarez B, Blanco-Gelaz MA, Gonzalez S, Rodrigo L, Lopez-Larrea C: Interaction between KIR3DL1 and HLA-B*57 supertype alleles influences the progression of HIV-1 infection in a zambian population. Hum Immunol 2005, 66(3):285-289.

17. Martin MP, Qi Y, Gao X, Yamada E, Martin JN, Pereyra F, Colombo S, Brown EE, Shupert WL, Phair J, et al: Innate partnership of HLA-B and KIR3DL1 subtypes against HIV-1. Nat Genet 2007, 39(6):733-740.

18. Soria A, Guerini FR, Bandera A, Bolognesi E, Uglietti A, Fusco C, Zucchi P, Maserati R, Rizzardini G, Clerici M, et al: KIR-HLA genotypes in HIV-infected patients lacking immunological recovery despite effective antiretroviral therapy. PLOS ONE 2011, 6(11):e27349.

19. Okulicz JF, Marconi VC, Landrum ML, Wegner S, Weintrob A, Ganesan A, Hale B, Crum-Cianflone N, Delmar J, Barthel V, et al: Clinical outcomes of elite controllers, viremic controllers, and long-term nonprogressors in the US Department of Defense HIV natural history study. J Infect Dis 2009, 200(11):1714-1723

20. Poropatich K, Sullivan DJ Jr: Human immunodeficiency virus type 1 longterm non-progressors: the viral, genetic and immunological basis for disease non-progression. J Gen Virol 2011, 92(Pt 2):247-268.

21. Bostik P, Kobkitjaroen J, Tang W, Villinger F, Pereira LE, Little DM, Stephenson ST, Bouzyk M, Ansari AA: Decreased NK cell frequency and function is associated with increased risk of KIR3DL allele polymorphism in simian immunodeficiency virus-infected rhesus macaques with high viral loads. J Immunol 2009, 182(6):3638-3649.

22. Koehler RN, Walsh AM, Moqueet N, Currier JR, Eller MA, Eller LA, WabwireMangen F, Michael NL, Robb ML, McCutchan FE, et al: High-throughput genotyping of KIR2DL2/L3, KIR3DL1/S1, and their HLA class I ligands using real-time PCR. Tissue Antigens 2009, 74(1):73-80.

23. Single RM, Martin MP, Gao X, Meyer D, Yeager M, Kidd JR, Kidd KK, Carrington M: Global diversity and evidence for coevolution of KIR and HLA. Nat Genet 2007, 39(9):1114-1119.

24. Alter G, Rihn S, Walter K, Nolting A, Martin M, Rosenberg ES, Miller JS, Carrington M, Altfeld M: HLA class I subtype-dependent expansion of KIR3DS1+ and KIR3DL1+ NK cells during acute human immunodeficiency virus type 1 infection. J Virol 2009, 83(13):6798-6805. 
25. Ravet S, Scott-Algara D, Bonnet E, Tran HK, Tran T, Nguyen N, Truong LX, Theodorou I, Barre-Sinoussi F, Pancino G, et al: Distinctive NK-cell receptor repertoires sustain high-level constitutive NK-cell activation in HIVexposed uninfected individuals. Blood 2007, 109(10):4296-4305.

26. Long BR, Ndhlovu LC, Oksenberg JR, Lanier LL, Hecht FM, Nixon DF, Barbour JD: Conferral of enhanced natural killer cell function by KIR3DS1 in early human immunodeficiency virus type 1 infection. J Virol 2008, 82 (10):4785-4792.

27. Zhang C, Zhang J, Tian Z: The regulatory effect of natural killer cells: do "NK-reg cells" exist? Cell Mol Immunol 2006, 3(4):241-254

28. Flores-Villanueva PO, Yunis EJ, Delgado JC, Vittinghoff E, Buchbinder S, Leung JY, Uglialoro AM, Clavijo OP, Rosenberg ES, Kalams SA, et al: Control of HIV-1 viremia and protection from AIDS are associated with HLA-Bw4 homozygosity. Proc Natl Acad Sci U S A 2001, 98(9):5140-5145.

29. D'Andrea A, Chang C, Franz-Bacon K, McClanahan T, Phillips JH, Lanier LL: Molecular cloning of NKB1, a natural killer cell receptor for HLA-B allotypes. J Immunol 1995, 155(5):2306-2310.

30. Liberatore C, Capanni M, Albi N, Volpi I, Urbani E, Ruggeri L, Mencarelli A, Grignani F, Velardi A: Natural killer cell-mediated lysis of autologous cells modified by gene therapy. J Exp Med 1999, 189(12):1855-1862.

31. Qing M, Li T, Han Y, Qiu Z, Jiao Y: Accelerating effect of human leukocyte antigen-Bw6 homozygosity on disease progression inChinese HIV-1 -infected patients. J Acquir Immune Defic Syndr 2006, 41(2):137-139.

32. Boulet S, Kleyman M, Kim JY, Kamya P, Sharafi S, Simic N, Bruneau J, Routy JP, Tsoukas CM, Bernard NF: A combined genotype of KIR3DL1 high expressing alleles and HLA-B*57 is associated with a reduced risk of HIV infection. AIDS 2008, 22(12):1487-1491.

33. Parsons MS, Wren L, Isitman G, Navis M, Stratov I, Bernard NF, Kent SJ: HIV infection abrogates the functional advantage of natural killer cells educated through KIR3DL1/HLA-Bw4 interactions to mediate anti-HIV antibody-dependent cellular cytotoxicity. J Virol 2012, 86(8):4488-4495.

34. Brodin P, Lakshmikanth T, Johansson S, Karre K, Hoglund P: The strength of inhibitory input during education quantitatively tunes the functional responsiveness of individual natural killer cells. Blood 2009, 113(11):2434-2441.

35. Cohen GB, Gandhi RT, Davis DM, Mandelboim O, Chen BK, Strominger JL, Baltimore D: The selective downregulation of class I major histocompatibility complex proteins by HIV-1 protects HIV-infected cells from NK cells. Immunity 1999, 10(6):661-671.

doi:10.1186/1471-2334-13-405

Cite this article as: Jiang et al:: KIR3DS1/L1 and HLA-Bw4-80I are associated with HIV disease progression among HIV typical progressors and long-term nonprogressors. BMC Infectious Diseases 2013 13:405.

\section{Submit your next manuscript to BioMed Central and take full advantage of:}

- Convenient online submission

- Thorough peer review

- No space constraints or color figure charges

- Immediate publication on acceptance

- Inclusion in PubMed, CAS, Scopus and Google Scholar

- Research which is freely available for redistribution 